\title{
Long-term nitrogen addition alters the community and energy channel but not diversity of soil nematodes in a subtropical forest
}

\author{
Qingqiu Zhou ${ }^{1}$, Xiaoli Wang ${ }^{2}$, Ying $\mathrm{Wu}^{3}$, Zhe Chen ${ }^{1}$, Debao $\mathrm{Li}^{1}$, Yuanhu Shao ${ }^{4}$, and \\ Jianping $\mathrm{Wu}^{1}$ \\ ${ }^{1}$ Yunnan University \\ ${ }^{2}$ State Key Laboratory of Plateau Ecology and Agriculture, Qinghai Academy of Animal \\ and Veterinary Sciences, Qinghai University \\ ${ }^{3}$ Institute of Botany Chinese Academy of Sciences \\ ${ }^{4}$ Henan University
}

August 11, 2020

\begin{abstract}
Summary 1. Research has indicated that increases in nitrogen $(\mathrm{N})$ deposition can greatly affect ecosystem processes and functions. There is limited information about the effects of long-term $\mathrm{N}$ addition on soil nematodes and their functional composition, although nematodes are the most abundant multicellular animals on Earth. 2. We conducted a field experiment in 2004 with four levels of $\mathrm{N}$ addition $(0,60,120$, and $240 \mathrm{~kg} \mathrm{~N}$ ha-1 $\mathrm{yr}-1)$ in a subtropical Cunninghamia lanceolata forest. Soil samples with three depths $(0-20,20-40$ and 40-60 cm) were collected and the community structure, diversity and trophic groups of soil nematodes were determined in 2014. 3. N addition significantly increased the abundance of bacterial- and fungal-feeding nematodes, but decreased the abundance of plant-feeding nematodes at the 0-20 cm soil layer. Accordingly, the plant parasite index and enrichment index decreased but the basal index and channel index increased, which weaken the importance of the plant-based energy channel, but enhance the importance of the fungal-based energy channel. N addition had no effects on the diversity of soil nematodes in three soil depths. Structural equation modeling analysis indicated that $\mathrm{N}$ loading directly changed plant-feeding (total $\mathrm{r} 2=0.42$ ) nematodes, or indirectly affected bacterial- $(\mathrm{r} 2=0.43)$, fungal- $(\mathrm{r} 2=0.31$ ) and plant-feeding nematodes via change soil nutrients, soil water content and $\mathrm{pH}$. 4. These findings suggest that $\mathrm{N}$ addition can change the community structure and energy channels soil nematodes, which would affect soil processes and food web functions in forest soils under future environmental change scenarios.
\end{abstract}

Title:Long-term nitrogen addition alters the community and energy channel but not diversity of soil nematodes in a subtropical forest

Authors: Qingqiu Zhou ${ }^{\mathrm{a}}$, Xiaoli Wang ${ }^{\mathrm{b}}$, Ying $\mathrm{Wu}^{\mathrm{a}}$, Zhe Chen ${ }^{\mathrm{a}}$, Debao $\mathrm{Li}^{\mathrm{a}}$, Yuanhu Shao ${ }^{\mathrm{c}, *}$, Jianping $\mathrm{Wu}^{\mathrm{a}, *}$

Affiliations: ${ }^{2}$ Yunnan Key Laboratory of Plant Reproductive Adaption and Evolutionary Ecology, School of Ecology and Environmental Sciences, Yunnan University, Kunming 650500, P.R. China

b State Key Laboratory of Plateau Ecology and Agriculture, Qinghai Academy of Animal and Veterinary Sciences, Qinghai University, Xining 810016, P.R. China.

${ }^{\mathrm{c}}$ Key Laboratory of Geospatial Technology for the Middle and Lower Yellow River Regions, Ministry of Education, College of Environment and Planning, Henan University, Kaifeng 475004, P.R. China

\section{Corresponding authors}


Prof. Jianping Wu

School of Ecology and Environmental Sciences, Yunnan University, Kunming 650500, China

E-mail: jianping.wu@ynu.edu.cn; Tel: +86-871-65031317; Fax: +86-871-65031317

or Prof. Yuanhu Shao E-mail: yshao@vip.henu.edu.cn.

Type of manuscript: Research Article Date of submission: Jul. 27, 2020

Number of text pages: 31 Number of words: 6800

Number of tables: 0 Number of figures: 5

Running title: $\mathrm{N}$ addition changes soil nematode communities.

\section{Summary}

1. Research has indicated that increases in nitrogen $(\mathrm{N})$ deposition can greatly affect ecosystem processes and functions. There is limited information about the effects of long-term $\mathrm{N}$ addition on soil nematodes and their functional composition, although nematodes are the most abundant multicellular animals on Earth.

2. We conducted a field experiment in 2004 with four levels of $\mathrm{N}$ addition $(0,60,120$, and $240 \mathrm{~kg} \mathrm{~N}$ $\left.\mathrm{ha}^{-1} \mathrm{yr}^{-1}\right)$ in a subtropical Cunninghamia lanceolata forest. Soil samples with three depths $(0-20,20-$ 40 and 40-60 cm) were collected and the community structure, diversity and trophic groups of soil nematodes were determined in 2014.

3. $\mathrm{N}$ addition significantly increased the abundance of bacterial- and fungal-feeding nematodes, but decreased the abundance of plant-feeding nematodes at the $0-20 \mathrm{~cm}$ soil layer. Accordingly, the plant parasite index and enrichment index decreased but the basal index and channel index increased, which weaken the importance of the plant-based energy channel, but enhance the importance of the fungalbased energy channel. $\mathrm{N}$ addition had no effects on the diversity of soil nematodes in three soil depths. Structural equation modeling analysis indicated that $\mathrm{N}$ loading directly changed plant-feeding (total $r^{2}$ $=0.42)$ nematodes, or indirectly affected bacterial- $\left(r^{2}=0.43\right)$, fungal- $\left(r^{2}=0.31\right)$ and plant-feeding nematodes via change soil nutrients, soil water content and $\mathrm{pH}$.

4. These findings suggest that $\mathrm{N}$ addition can change the community structure and energy channels soil nematodes, which would affect soil processes and food web functions in forest soils under future environmental change scenarios.

Key-words:nitrogen deposition, soil biology, soil nematodes, forest ecosystem, global change

\section{Introduction}

The deposition of reactive nitrogen $(\mathrm{N})$ from the atmosphere to the Earth's surface has been increasing globally (Vitousek et al.1997; Li et al. 2020; Xie et al. 2020) and is predicted to increase to as much as $200 \mathrm{Tg} \mathrm{N} \mathrm{yr}{ }^{-1}$ by 2050 (Vitouseket al. 1997; Galloway et al. 2008). In China, the increases in N deposition caused by rapid agricultural and industrial development and its pollution on ecosystems has been of wide concern over the past decade (Cui et al. 2013; Liu et al. 2013; Yuet al. 2019). The effects of $\mathrm{N}$ deposition on terrestrial ecosystems include changes in carbon (C) and N cycling (Isbell et al. 2013; Zhang et al. 2020), plant species richness (Luet al. 2010; Wu et al. 2013), soil community structure (Liet al. 2019; Yang et al. 2020) and human health (Chenet al. 2019; De Marco et al. 2019). The effects of $\mathrm{N}$ deposition on soil nematode communities, however, are incompletely understood.

Nematodes are the most abundant multicellular animals on Earth (van den Hoogen et al. 2019). They are important components of soil food webs (De Long 2017). Abundance and diversity of nematodes are correlated with many geochemical processes such as ecosystem succession, litter decomposition and $\mathrm{N}$ cycling (Fu et al. 2000; Neher et al.2012; Zhao et al. 2012). Several related studies have shown that the development and characteristics of nematode communities were greatly affected by plant community characteristics (Li et al. 2007; de la Peña et al. 2016; Shao et al. 2016; Zhao et al. 2019). Because nematodes are sensitive to 
external disturbances (e.g., land-use change and environmental pollution) and nematode communities are generally regarded as effective indicators of the health and stability of soil food webs (Bongers 1990; Powell 2007; Zhao et al. 2013). Researchers have therefore concluded that the assessment of an ecosystem's renewal efficiency and adaptability after changes in site conditions should include belowground components including soil nematodes (Todd et al. 2006). In recent years, studies of nematode communities have focused on their responses to changes in agricultural management and land-use. For example, cropping systems have obvious effects on soil nematode communities (Treonis et al. 2018). In addition, fertilization can alter nematode communities by affecting the soil microbial communities and the soil abiotic properties (Liu et al.2016; Li et al. 2018a; Zhao et al. 2018).

The effects of excess $\mathrm{N}$ deposition on soil nematodes have not been well understood. Previous reports indicated that $\mathrm{N}$ deposition increased the abundance of a particular taxon or of several trophic groups (Lianget al. 2009; Shaw et al. 2019). In another report, $\mathrm{N}$ deposition generally decreased the abundance of nematodes in $\mathrm{N}$-rich but phosphorus-poor soils (Zhao et al. 2014). Other researchers found that long-term $\mathrm{N}$ enrichment reduced the abundance of bacterial-feeding, fungal-feeding, plant-feeding and omnivorous-predatory nematodes because of soil acidification (Chen et al. 2015) or because of biotic interactions (Shao et al. 2017; Shaw et al. 2019). Generally, changes in the community compositions of soil nematodes may alter energy fluxes in soil food webs (Shao et al. 2019), where the energy flow and stability of food webs can be closely linked (Rooney and McCann, 2012; Schwarz et al. 2017).

In the current study, we focus on the effects of $\mathrm{N}$ addition on soil nematodes in subtropical forest. Tropical and subtropical forests contribute one-third to terrestrial primary production and have high species richness, which function as important C sinks (Brookshireet al. 2012; Ferreira et al. 2018). However, global change phenomenon such as $\mathrm{N}$ deposition could nevertheless have substantial effects on tropical and subtropical forest ecosystems (Hedin et al. 2005; Lewis et al. 2009; Gerber et al. 2010). Therefore, exploring the responses of soil nematode community and the changes in the energy channel in soil food webs to a long-term $\mathrm{N}$ addition in tropical and subtropical forests is of great importance to ecosystem stability. In the present study, we conducted a long-term N-loading experiment to determine how $\mathrm{N}$ addition affects the community structure of soil nematodes in a subtropical forest. We hypothesized that 1) $\mathrm{N}$ addition will alter the energy channel that indicated by the structure of nematode community; and 2) different trophic groups of nematodes would have different responses to $\mathrm{N}$ addition with the direct or indirect pathways. These hypotheses were suggested by previous findings, which reported that $\mathrm{N}$ deposition and other environmental factors can affect soil nematode communities and energy channels (Zhaoet al. 2014; Shao et al. 2017; Shao et al. 2019).

\section{Materials and methods}

\section{Site description}

This study was conducted at the Guanzhuang National Forestry Farm, Sanming City, Fujian Province, South China $\left(117^{\circ} 43^{\prime} \mathrm{E}, 26 \mathrm{deg} 30^{\prime} \mathrm{N}\right)$. This region has a subtropical monsoon climate with a mean annual temperature ranging from 18.8 to $19.6 \mathrm{degC}$ and a mean annual precipitation ranging from 1,606 to 1,650 mm (Wu et al. 2013). The Farm contains a 5173-ha Chinese fir (Cunninghamia lanceolata) planation, which was planted in 1992 (Fan et al. 2014). The test soil is classified as a mountain red soil. Annual average wet $\mathrm{N}$ deposition (including soil nitrate and ammonium nitrogen) resulting from rainfall in the Sanming region was reported to range from 4.2 to $5.7 \mathrm{~g} \mathrm{~N} \mathrm{~m}^{-2} \mathrm{year}^{-1}$ (Fan et al. 2014).

\section{Experimental design}

In December 2003, 12 experimental plots were established in a 6-ha section of the Chinese fir plantation. Each plot was $20 \mathrm{~m} \mathrm{x} 20 \mathrm{~m}$ and had similar site conditions. In each plot, a central area of $15 \mathrm{~m} \mathrm{x} 15 \mathrm{~m}$ was designated for treatments, arranging one of four levels of N. The treatment codes N0, N1, N2, and N3 indicated the loading of $0,60,120$, and $240 \mathrm{~kg} \mathrm{~N}^{-1} \mathrm{yr}^{-1}$, respectively. Each treatment was represented by three randomly assigned replicate plots. Urea $\left[\mathrm{CO}\left(\mathrm{NH}_{2}\right)_{2}\right]$ was used as the $\mathrm{N}$ source, and the required quantity was dissolved in $20 \mathrm{~L}$ of water per plot. From January 2004 to January 2014 (when plots were sampled), $20 \mathrm{~L}$ of $\mathrm{N}$ solution was sprayed onto the soil surface in the central area $(15 \mathrm{~m} \mathrm{x} 15 \mathrm{~m})$ of each plot 
once per month. Control plots (N0) were sprayed with the same volume of water without $\mathrm{CO}\left(\mathrm{NH}_{2}\right)_{2}$.

\section{Soil sampling and the extraction and identification of nematodes}

In January 2014 (after 10 years of $\mathrm{N}$ application), soil cores were collected from each plot (the treated central area) at 0-20 cm, 20-40 cm, and 40-60 cm soil depths. In each plot, five soil cores $(3 \mathrm{~cm}$ in diameter) at each depth were randomly taken and combined to form one composite sample per depth per plot. The litter layer at the sample locations was removed before cores were collected. There were 36 soil samples (3 depths x 12 plots) in total.

After visible roots and stones were removed, the soil samples were passed through a 2-mm-mesh sieve and then stored at $4 \mathrm{degC}$ for chemical analysis and nematode extraction. Soil water content (SWC, \%, g of water per $100 \mathrm{~g}$ dry soil) was measured by comparing weights before and after oven-drying at $105 \operatorname{degC}$ for $24 \mathrm{~h}$, and soil $\mathrm{pH}$ was determined in a $1: 2.5(\mathrm{w} / \mathrm{v})$ soil suspension. Concentrations of total N (TN, g/ $\mathrm{kg}$ dry soil) and total phosphorus (TP, g/kg dry soil) were measured according to Zhou et al. (2019). Total $\mathrm{C}$ (TC, g/kg dry soil) was determined using an elemental analyzer (Perkin Elmer Instruments series II, USA). Contents of soil nitrate $\left(\mathrm{NO}_{3}{ }^{-}-\mathrm{N}, \mathrm{mg} / \mathrm{kg}\right.$ fresh soil) and ammonium nitrogen $\left(\mathrm{NH}_{4}{ }^{+}-\mathrm{N}, \mathrm{mg} / \mathrm{kg}\right.$ fresh soil) were determined as previously described (Chen et al. 2015). Available P (AP, $\mathrm{mg} / \mathrm{kg}$ dry soil) was extracted with a sodium bicarbonate solution $(0.5 \mathrm{M}, 30$ min extraction), and the extracted phosphate was then quantified by the molybdenum blue procedure (Zhao et al.2018).

Nematodes were extracted from a 100-g subsample of fresh soil from each composite soil sample with Baermann funnels (Gray, 1984). The extracted nematodes were collected in a $4 \%$ formalin solution, and then counted and identified with a DIC microscope (ECLIPSE 80i, Nikon). The first 100 individuals encountered were identified to the genus or family level and classified into four trophic groups, including bacterial-feeding nematodes $(\mathrm{BF})$, plant-feeding nematodes $(\mathrm{PF})$, fungal-feeding nematodes (FF) and omnivorous-predatory nematodes (OP) (Bongers and Bongers, 1998; Yeates et al. 1993).

\section{Statistical analysis}

The total number of soil nematodes in each trophic group was converted to the total number of individuals per $100 \mathrm{~g}$ of dry soil. The following indices were used to determine nematode diversity as described by Zhao et al. (2014):

Shannon-Wiener diversity index $\left(H^{\prime}\right), H^{\prime}=-\sum \operatorname{Pi} \ln \mathrm{Pi}(1)$

Pielou evenness index $(J), J=\frac{H^{\prime}}{H^{\prime} \max }$

$H^{\prime} \max =\ln S(3)$

Simpson dominance index, $\lambda=\sum P i^{2}(4)$

Margalef richness index, $S R=\frac{S-1}{\ln N}(5)$

where $p i$ is the proportion of the $i$ th species $(i=1,2,3 \ldots \mathrm{S}), \mathrm{S}$ is the number of nematode categories in one soil sample, and $N$ is the total number of individuals of all nematode categories.

Two maturity indices (MI25 and PPI) were also calculated to represent the diversity of nematode life history based on colonizer-persister (c-p) values; c-p values range from 1 to 5 , i.e., from colonizer ( $r$-strategy) to persister ( $K$-strategy) (Bongers, 1990). MI25 is a maturity index for free-living nematodes (c-p value $=$ 2, 3, 4, and 5) except plant-feeding nematodes and juveniles, and PPI is a maturity index for plant-feeding nematodes (Bongers, 1990). These indices are calculated as follows:

$M I 25=\sum v(i)^{c p 2-5} \times f(i)^{c p 2-5}(6)$

$P P I=\sum v(i)^{c p 1-5} \times f(i)^{c p 1-5}(7)$

where $v(i)$ is the c-p value of the taxon, and $f(i)$ is the proportional abundance of this taxon relative to the total abundance of free-living nematodes (for MI25) or plant-feeding nematodes (for PPI) in one soil 
sample.

The functional diversity of nematodes in each soil sample was determined by calculating the enrichment index (EI), structure index (SI), basal index (BI), and channel index (CI). According to Ferris et al. (2001), the EI value is the expected response of the opportunistic Ba1 (bacterial-feeding nematodes with c-p $=1$ ) and Fu2 (fungal-feeding nematodes with c-p $=2$ ) to abundant resources; the SI value indicates the conditions of the soil food web. BI and CI values are used to evaluate the effects of soil management methods on nematode communities (Berkelmans et al. 2003). These indices were calculated as follows:

$E I=100 \times\left(\frac{e}{b+e}\right)(8)$
$S I=100 \times\left(\frac{s}{b+s}\right)(9)$
$B I=100 \times\left(\frac{b}{b+e+s}\right)(10)$
$C I=100 \times\left(\frac{e f}{e b+e f}\right)(11$

where $e$ is the enrichment of Ba1 and Fu2; $b$ is the basal component of Ba2 and Fu2; $s$ is the structural component containing the guilds of Ba3-5, Fu3-5, Om3-5, and Pr2-5; ef is a product of the abundance $\mathrm{x}$ weight value of the Fu2 guild; and $e b$ is a product of the abundance $\mathrm{x}$ weight value of the Ba1 guild.

Two-way ANOVAs were conducted to assess the effects of two main factors ( $N$ addition and sampling depth, $\mathrm{N}$ and $\mathrm{D})$ and their interactions $\left(\mathrm{N}^{*} \mathrm{D}\right)$ on all dependent variables. One-way ANOVAs were used to compare the four treatments. If ANOVAs were significant, means were compared with an LSD test at $P<$ 0.05. SPSS Statistics 19.0 was used for statistical analyses (SPSS Inc., Chicago, USA). Structural equation modeling (SEM) was performed by "lavaan" package in R (Rosseel, 2012), to analyze hypothetical pathways that may explain how $\mathrm{N}$ loading affected different trophic groups of soil nematodes. Before we employed the model, we assessed model identification according to $t$-Rule, which the number of nonredundant elements in the covariance matrix of the observed variables must be greater than or equal to the number of unknown parameters (https://stat.utexas.edu/software-faqs/lisrel/146-training/software/655lisrel-assessing-model-identification). The response variables (showed in the Supplementary Table 1) for soil total $\mathrm{C}$, total $\mathrm{N}$ and total $\mathrm{P}$; for $\mathrm{NO}_{3}{ }^{-}-\mathrm{N}, \mathrm{NH}_{4}{ }^{+}-\mathrm{N}$ and available $\mathrm{P}$ were indicated by principal component scores (both PC1 scores were employed). The co-occurrence networks of different nematode genera were used to determine the stability of their coexistence under different $\mathrm{N}$ levels; these networks were constructed using the "wgcna" package in R based on the Spearman correlation matrix (Langfelder and Horvath, 2012).

\section{Results}

\section{Soil nematode abundance and diversity}

The abundance of total nematodes and of BF and OP groups significantly decreased with soil depth (Fig. 1). Two-way ANOVAs showed that $\mathrm{N}$ loading significantly changed $\mathrm{BF}(P<0.01)$ and $\mathrm{PF}(P=0.02)$ groups. At $0-20 \mathrm{~cm}$ depth, N3 significantly increased the abundance of total nematodes and of $\mathrm{BF}$ and $\mathrm{FF}$ groups but significantly decreased the abundance of PF group.

Two-way ANOVAs indicated that soil nematode diversity was not significantly affected by $\mathrm{N}$ loading but was significantly affected by soil depth (Fig. 2). The Shannon-Weiner (Fig. 2a) and Margalef richness indices (Fig. 2d) decreased with soil depth, while the Simpson dominance index (Fig. 2c) increased with soil depth.

\section{Nematode}

\section{ecological indices}

N loading significantly decreased the values of MI25 (Fig. 3a), EI (Fig. 3c) and SI (Fig. 3d) while significantly increased the BI value (Fig. 3e) at 0-20 cm. MI25 (Fig. 3a) and SI (Fig. 3d) values significantly decreased with soil depth, and the CI value (Fig. 3f) significantly increased with soil depth. At 20-40 cm, the values of EI, SI, BI, and CI differed between N2 and N3.

\section{Co-occurrence patterns in the N-loading system}


A co-occurrence network was built for the identified nematodes at the genus level. Compared with N0, there was a slight rising of positively correlated edges at N1 treatment, then decreased at N2 and N3 treatments (Fig. 4a). N1 treatment had the most positive correlations (74.2\%) and network connections (31 edges), while N2 and N3 levels had more negative correlations. The structure values in the N-loading networks were greater than or equal to those in N0 (Fig. 4b).

\section{Pathways determining the abundances of soil nematode trophic groups}

SEM analysis was performed to reveal the relationships between the abundance of nematode trophic groups and environmental attributes under a good model fit using $\chi^{2}$ test $\left(\chi^{2}=7.55\right.$, Fig. 5). As for the four nematode trophic groups, the SEM explained $0.8-42.5 \%$ of total variance with $\mathrm{N}$ loading. The abundance of the PF group $\left(r^{2}=0.42\right)$ was directly affected by $\mathrm{N}$ loading $(P<0.001)$, and was indirectly affected by soil $\mathrm{pH}$ under N-loading regulation $(P<0.001$, Fig. 5a). By altering soil available nutrients and soil water content, $\mathrm{N}$ loading significantly changed the abundance of $\mathrm{FF}\left(P<0.001, r^{2}=0.31\right)$ and BF groups $\left(P<0.01, r^{2}=0.43\right)$. Moreover, $\mathrm{N}$ loading was as a whole beneficial to the fungal- (Fig. 5b; Table S2) and bacterial-feeding (Fig. 5c; Table S2) nematodes, while was detrimental for the plant-feeding nematodes (Fig. 5d; Table S2).

\section{Discussion}

In the present study, long-term $\mathrm{N}$ loading affected the abundance of nematode trophic groups in shallow soil of a subtropical Chinese fir forest. The N3 treatment, for example, significantly increased total, bacteriaand fungal-feeding nematode abundances but significantly decreased the abundance of plant-feeding group (Fig. 1), which is consistent with the first hypothesis. Because the population dynamics of nematode trophic groups are closely related with their functional roles (Mueller et al. 2016; Shaw et al. 2019), N addition would also affect nematode ecological indices, i.e., MI25, EI, SI, BI, and CI (Fig. 3). For example, N loading significantly decreased the MI25 value at $0-20 \mathrm{~cm}$ soil depth but not at deeper soil layer, which supported that $\mathrm{N}$ loading only affected bacterial-feeding nematodes in the shallow soil layer. The values of MI25 are determined by c-p2 to c-p4 values (Zhao et al. 2014), however, the values of c-p3 and c-p4 guilds did not respond to $\mathrm{N}$ loading (Fig. S1 and S2), so the increase of bacterial- and fungal-feeding nematode abundances to $\mathrm{N}$ loading was caused by the increase in the abundance of c-p2 values in our study. Therefore, we considered that the long-lived functional guilds with higher c-p values, e.g., the OP group, are more vulnerable to environmental changes and require longer time to recover from disturbances than fungal- and bacterial-feeding nematodes (Ferriset al. 2001; Liang et al. 2009). Consistent with that view, our results showed that $\mathrm{N}$ addition tended to reduce the abundance of OP group. Furthermore, the SI value, which is mainly determined by the abundance of omnivorous and predatory nematodes (Ferris et al. 2001), also declined at 0-20 cm soil depth in response to $\mathrm{N}$ loading (Fig. 2d). The SI value is generally found to be high in undisturbed natural systems (Ferris et al. 2001; Zhao et al. 2013), which suggests that N addition may bring some negative effects on soil ecosystem of the subtropical forests.

Another interesting finding is that $\mathrm{N}$ loading decreased the EI value, but increased the CI value (Fig. 3). EI reflects resource availability and decomposing capacity of primary decomposers of soil food web, while $\mathrm{CI}$ is an indication of fungal-feeding nematodes as the dominant energy channel in soil food web (Ferris et al. 2001; Shaw et al.2019). Therefore, the consideration of both indices provides useful information on soil nutrient status. A previous study suggested that a higher EI value and a lower CI value indicated a resource-rich soil environment dominated by bacterial-feeding nematodes (Liang et al. 2009). Our finding that $\mathrm{N}$ loading decreased the EI value and increased the $\mathrm{CI}$ value indicates that $\mathrm{N}$ loading diminished the relative importance of a bacterial-dominated energy channel. Moreover, the, A significant increase in the $\mathrm{BI}$ value indicated a positive effect of $\mathrm{N}$ loading on both $\mathrm{Fu} 2$ and $\mathrm{Ba} 2$ guilds (Fig. S2), since BI value is mainly determined by Fu2 and Ba2 guilds (Zhaoet al. 2014). N loading also increased the abundance of fungal-feeding nematodes, suggesting that the relative importance of fungal energy channel increased with $\mathrm{N}$ loading. However, $\mathrm{N}$ loading significantly reduced the abundance of plant-feeding nematodes (Fig. 1). The results differed from those of Shao et al. (2017), who found that $\mathrm{N}$ inputs did not significantly affect the abundance of plant-feeding nematodes. The reason would be that we used a gradient of N-loading rates, which probably provides more information than a single rate in that Shao et al. (2017). Because the quantity 
of nitrogen applied regulated the responses of soil nematode communities (Lokupitiya et al. 2000; Wei et al. 2012; Liet al. 2013).

It is worth noting that $\mathrm{N}$ addition had no effects on the diversity of soil nematodes (Fig. 2). Both the Shannon-Wiener diversity and Margalef richness were similar with or without N loading and significantly decreased with soil depth. Our results are similar with previous results from a secondary tropical forest (Zhao et al.2014) but not with results from a temperate forest (Sun et al.2013) or a grassland (Wei et al. 2012), where N addition reduced soil nematode diversity. The Simpson dominance index in N2 treatment was significantly higher at 40-60 cm soil depth than at the other two soil depths, indicating that a certain concentration of $\mathrm{N}$ addition might increase the dominant position of some nematode species in deep soil. Our results indicated that nematode diversity only showed some dynamics along different soil depth but not $\mathrm{N}$ treatments. The explanation would be that the changes of soil nematode community structure did not always reflect the diversity, since the complexity of soil micro-food web in natural ecosystems (Rooney and McCann, 2012; Li et al. 2013). Our recent report also showed that changes in soil microbial community composition would mainly contribute to the litter decomposition process compared with soil microbial diversity (Wu et al. 2019), which supports the phenomenon of soil nematode in this study.

Structural equation modeling was performed to test the second hypothesis how $\mathrm{N}$ addition affects the trophic groups of soil nematodes with direct or indirect pathways. We found that $\mathrm{N}$ loading reduced the abundance of plant-feeding nematodes either directly or indirectly via an alteration in soil $\mathrm{pH}$. The negative effect of $\mathrm{N}$ loading on plant-feeding nematodes may result from the negative effects on plants, for that $\mathrm{N}$ addition may reduce plant diversity, aboveground biomass, and fine root biomass of understory vegetation (Lu et al. 2010; Lu et al. 2011; Wuet al. 2013). A decrease in the aboveground biomass and fine root biomass of understory vegetation may lead to a reduction in food resources for plant-feeding nematodes (Wu et al. 2013; Fanet al. 2014). Our previous reports also indicated that $\mathrm{N}$ loading decreased soil $\mathrm{pH}$ in the studied region (Wu et al. 2013; Shenet al. 2019) and other report also proved it in Northeast China (Liang et al. 2009). Soil acidification may indirectly affect plant-feeding nematodes by decreasing soil base cations and altering the abiotic environment (Chen et al. 2015).

$\mathrm{N}$ loading increased the abundance of fungal- and bacterial-feeding nematodes apparently through an increase in the concentration of soil available nutrients, which presumably supported increases in food resources for them. On one hand, the decrease of soil $\mathrm{pH}$ in our study did not exert a negative impact on the fungaland bacterial-feeding nematodes, which was supported by the SEM analysis. Indeed, an increase in the individuals of bacterial-feeding nematodes was measured. Commonly, soil acidification induced by $\mathrm{N}$ addition can inhibit soil microbial growth and bacterial biomass accumulation (Rousk et al. 2010; Chen et al. 2015; Li et al. 2018b), which is supposed to lead a reduction of food resources for soil fungal- and bacterialfeeding nematodes, and eventually result in a decline in their abundance. On the other hand, $\mathrm{N}$ loading may change the community structure of bacterial-feeding nematodes by changing their environmental adaptations. Generally, soil condition with plentiful food resources are beneficial to those nematodes with short generation cycles (Bongers, 1990; Bongers \& Ferris, 1999; Liang et al. 2009), i.e., Ba1 and Ba2 guilds. The elevated N stress made bacterial-feeding nematodes change their survival strategy and transform community structure to abundant $r$-strategy colonizer (Ba1 and Ba2 guilds) under $\mathrm{N}$ addition (Zhao et al. 2015a). The cooccurrence network of nematodes taxa analysis showed that nodes and edges varied in different $\mathrm{N}$ treatments (Fig. 4), which supported our inference that $\mathrm{N}$ addition can change the community structure and stability of soil nematode communities (Zhao et al. 2015b). All these results indicate that nematodes changed by $\mathrm{N}$ addition, whether they can finally reach a new equilibrium in response to gradually elevated $\mathrm{N}$ loading requires more studies.

\section{Conclusions}

A 10-year field N-loading experiment was conducted and the responses of soil nematode communities to $\mathrm{N}$ addition were investigated in a subtropical Chinese fir forest. We first found that long-term $\mathrm{N}$ loading affected the abundance and community structure of soil nematodes in the surface soil layer. $\mathrm{N}$ addition increased the abundances of total nematodes, bacterial-feeding nematodes, and fungal-feeding nematodes, 
but decreased the abundance of plant-feeding nematodes at 0-20 cm soil depth. Secondly, SEM and network analyses verified that $\mathrm{N}$ addition changed the nematode community structure. $\mathrm{N}$ addition directly affected plant-feeding nematodes and weakened the importance of the plant-based energy channel and enhanced the importance of the fungal-based energy channel. Effects of $\mathrm{N}$ addition on soil bacterial-, fungal- and plantfeeding nematodes were contributed the resource inputs and soil physico-chemical variations indirectly. These responses of community structure and trophic groups of soil nematodes may therefore affect soil processes and food web functions under $\mathrm{N}$ addition in forest ecosystems.

\section{Acknowledgements}

We are grateful to Fangfang Shen, Wenfei Liu and Qingying Meng for their kind assistance with the field sampling. This work was funded by National Natural Science Foundation of China (Nos. 31971497, 31570444) and by "Double First-Class" funding from Yunnan University (No. C176220100003).

\section{Author Contributions}

J. Wu and Q. Zhou conceived of and designed the experiments. Q. Zhou, J. Wu, Y. Shao, D. Li, and Z. Chen analyzed the data and drew the figures. The authors jointly wrote the manuscript.

\section{Competing financial interests}

The authors declare no competing financial interests.

\section{Data accessibility}

Data available from the Dryad Digital Repository https://datadryad.org/stash/dataset/doi:10.5061/dryad.x3ffbg7gg (Zhou \& Wu 2020).

\section{References}

Berkelmans, R., Ferris, H., Tenuta, M. \& van Bruggen, A.H.C. (2003) Effects of long-term crop management on nematode trophic levels other than plant feeders disappear after 1 year of disruptive soil management.Applied Soil Ecolog,y 23, 223-235.

Bongers, T. (1990) The maturity index: an ecological measure of environmental disturbance based on nematode species composition. Oecologia, 83, 14-19.

Bongers, T. \& Bongers, M. (1998) Functional diversity of nematodes.Applied Soil Ecology, 10, 239-251.

Bongers, T. \& Ferris, H. (1999) Nematode community structure as a bioindicator in environmental monitoring. Trends in Ecology 83 Evolution, 14, 224-228.

Brookshire, E.N.J., Hedin, L.O., Newbold, J.D., Sigman, D.M. \& Jackson, J.K. (2012) Sustained losses of bioavailable nitrogen from montane tropical forests. Nature Geoscience, 5, 123-126.

Chen, D., Lan, Z., Hu, S. \& Bai, Y. (2015) Effects of nitrogen enrichment on belowground communities in grassland: Relative role of soil nitrogen availability vs. soil acidification. Soil Biology and Biochemistry, 89, 99-108.

Chen, G., Xiang, H., Mao, Z., Huo, W., Guo, Y., Wang, C. \& Li, S. (2019) Is long-term exposure to air pollution associated with poor sleep quality in rural China? Environment International, 133,105205.

Cui, S., Shi, Y., Groffman, P. M., Schlesinger, W. H. \& Zhu, Y. (2013) Centennial-scale analysis of the creation and fate of reactive nitrogen in China (1910-2010). Proceedings of the National Academy of Sciences of the United States of America, 110, 2052-2057.

de la Peña, E., Baeten, L., Steel, H., Viaene, N., De Sutter, N., De Schrijver, A., et al. (2016) Beyond plant-soil feedbacks: mechanisms driving plant community shifts due to land-use legacies in post-agricultural forests. Functional Ecology, 30 , 1073-1085. 
De Long, J. R. (2017) Nematodes, exotic earthworms and nitrogen addition: interactions between global change factors lead to cancellation effects. Journal of Animal Ecology, 86 , 705-707.

De Marco, A., Proietti, C., Anav, A., Ciancarella, L., D’Elia, I., Fares, S., . \& \& Leonardi, C. (2019) Impacts of air pollution on human and ecosystem health, and implications for the National Emission Ceilings Directive: Insights from Italy. Environment International, $125,320-333$.

Fan, H., Wu, J., Liu, W., Yuan, Y., Huang, R., Liao, Y., et al.(2014) Nitrogen deposition promotes ecosystem carbon accumulation by reducing soil carbon emission in a subtropical forest. Plant and Soil, 379, 361-371.

Fang, Y., Yoh, M., Koba, K., Zhu, W., Takebayashi, Y.U., Xiao, Y.,et al. (2011) Nitrogen deposition and forest nitrogen cycling along an urban-rural transect in southern China. Global Change Biology, 17, 872-885.

Ferreira, J., Lennox, G.D., Gardner, T.A., Thomson, J.R., Berenguer, E., Lees, A.C., et al. (2018) Carbonfocused conservation may fail to protect the most biodiverse tropical forests. Nature Climate Change, $\mathbf{8}$, 744-749.

Ferris, H., Bongers, T. \& de Goede, R.G.M., (2001) A framework for soil food web diagnostics: extension of the nematode faunal analysis concept.Applied Soil Ecology, 18, 13-29.

Fu, S., Coleman, D.C., Hendrix, P.F. \& Crossley, D.A., (2000) Responses of trophic groups of soil nematodes to residue application under conventional tillage and no-till regimes. Soil Biology and Biochemistry, 32 , 1731-1741.

Galloway, J.N., Dentener, F.J., Capone, D.G., Boyer, E.W., Howarth, R.W., Seitzinger, S.P., et al. (2004) Nitrogen cycles: past, present, and future. Biogeochemistry, 70 , 153-226.

Galloway, J.N., Townsend, A.R., Erisman, J.W., Bekunda, M., Cai, Z., Freney, J.R., et al. (2008) Transformation of the nitrogen cycle: recent trends, questions, and potential solutions. Science,320 , 889-892.

Gerber, S., Hedin, L.O., Oppenheimer, M., Pacala, S.W. \& Shevliakova, E. (2010) Nitrogen cycling and feedbacks in a global dynamic land model.Global Biogeochemical Cycles, 24, GB1001.

Gray, N.F. (1984) Ecology of nematophagous fungi: comparison of the soil sprinkling method with the Baermann funnel technique in the isolation of endoparasites. Soil Biology and Biochemistry, 16 , 81-83.

Hedin, L.O., Brookshire, E.N.J., Menge, D.N.L. \& Barron, A.R. (2005) The nitrogen paradox in tropical forest ecosystems. Annual Review of Ecology, Evolution, and Systematics, 40 , 613-635.

Isbell, F., Reich, P.B., Tilman, D., Hobbie, S.E., Polasky, S. \& Binder, S. (2013) Nutrient enrichment, biodiversity loss, and consequent declines in ecosystem productivity. Proceedings of the National Academy of Sciences of the United States of America, 110, 11911-11916.

Langfelder, P. \& Horvath, S. (2012) Fast R functions for robust correlations and hierarchical clustering. Journal of Statistical Software, 46 , i11.

Lewis, S.L., Lopez-Gonzalez, G., Sonké, B., Affum-Baffoe, K., Baker, T.R., Ojo, L.O., et al. (2009) Increasing carbon storage in intact African tropical forests. Nature, 457, 1003-1006.

Li, J., Wang, D., Fan, W., He, R., Yao, Y., Sun, L., et al.(2018a) Comparative effects of different organic materials on nematode community in continuous soybean monoculture soil. Applied Soil Ecology, 125 , 12-17.

Li, Q., Bai, H., Liang, W., Xia, J., Wan, S. \& van der Putten, W.H. (2013) Nitrogen addition and warming independently influence the belowground micro-food web in a temperate steppe. PLoS One,8, e60441.

Li, Y., Bezemer, T.M., Yang, J., Lü, X., Li, X., Liang, W., et al. (2019) Changes in litter quality induced by $\mathrm{N}$ deposition alter soil microbial communities. Soil Biology and Biochemistry,130 , 33-42.

Li, Y., Feng, J., Chen, J. \& Wu, J. (2007) Original vegetation type affects soil nematode communities. Applied Soil Ecology,35 , 68-78. 
Li, Y., Sun, J., Tian, D., Wang, J., Ha, D., Qu, Y., et al.(2018b) Soil acid cations induced reduction in soil respiration under nitrogen enrichment and soil acidification. Science of the Total Environment, 615 , $1535-1546$.

Li, Z., Hastings, M. G., Walters, W. W., Tian, L., Clemens, S. C., Song, L., . . \& Fang, Y. (2020) Isotopic evidence that recent agriculture overprints climate variability in nitrogen deposition to the Tibetan Plateau. Environment International, $138,105614$.

Liang, W., Lou, Y., Li, Q., Zhong, S., Zhang, X. \& Wang, J. (2009) Nematode faunal response to long-term application of nitrogen fertilizer and organic manure in Northeast China. Soil Biology and Biochemistry,41 , 883-890.

Liu, T., Whalen, J.K., Ran, W., Shen, Q. \& Li, H. (2016) Bottom-up control of fertilization on soil nematode communities differs between crop management regimes. Soil Biology and Biochemistry,95 , 198-201.

Liu, X., Zhang, Y., Han, W., Tang, A., Shen, J., Cui, Z., et al.(2013) Enhanced nitrogen deposition over China. Nature,494, 459-462.

Lokupitiya, E., Stanton, N.L., Seville, R.S. \& Snider, J.R. (2000) Effects of increased nitrogen deposition on soil nematodes in alpine tundra soils. Pedobiologia, 44 , 591-608.

Lu, X., Mo, J., Gilliam, F.S., Yu, G., Zhang, W., Fang, Y., et al. (2011) Effects of experimental nitrogen additions on plant diversity in tropical forests of contrasting disturbance regimes in southern China. Environmental Pollution, 159, 2228-2235.

Lu, X., Mo, J., Gilliam, F.S., Zhou, G. \& Fang, Y. (2010) Effects of experimental nitrogen additions on plant diversity in an old-growth tropical forest. Global Change Biology, 16 , 2688-2700.

Mueller, K.E., Blumenthal, D.M., Carrillo, Y., Cesarz, S., Ciobanu, M., Hines, J., et al. (2016) Elevated $\mathrm{CO}_{2}$ and warming shift the functional composition of soil nematode communities in a semiarid grassland. Soil Biology and Biochemistry, 103 , 46-51.

Neher, D.A., Weicht, T.R. \& Barbercheck, M.E. (2012) Linking invertebrate communities to decomposition rate and nitrogen availability in pine forest soils. Applied Soil Ecology, 54 , 14-23.

Powell, J.R. (2007) Linking soil organisms within food webs to ecosystem functioning and environmental change. Advances in Agronomy. Academic Press, pp. 307-350.

Rooney, N. \& McCann, K.S. (2012) Integrating food web diversity, structure and stability. Trends in Ecology Evolution,27 , 40-46.

Rosseel, Y. (2012) lavaan : an R package for structural equation modeling. Journal of Statistical Software, $48,1-36$.

Rousk, J., Baath, E., Brookes, P.C., Lauber, C.L., Lozupone, C., Caporaso, J.G., et al. (2010) Soil bacterial and fungal communities across a pH gradient in an arable soil. The ISME Journal, 4, 1340-1351.

Schwarz, B., Barnes, A.D., Thakur, M.P., Brose, U., Ciobanu, M., Reich, P.B., et al. (2017) Warming alters the energetic structure and function but not resilience of soil food webs. Nature Climate Change, 7, 895-900.

Shao, Y., Wang, X., Zhao, J., Wu, J., Zhang, W., Neher, D.A., et al. (2016) Subordinate plants sustain the complexity and stability of soil micro-food webs in natural bamboo forest ecosystems. Journal of Applied Ecology, 53, 130-139.

Shao, Y., Zhang, W., Eisenhauer, N., Liu, T., Ferlian, O., Wang, X., et al. (2019) Exotic earthworms maintain soil biodiversity by altering bottom-up effects of plants on the composition of soil microbial groups and nematode communities. Biology and Fertility of Soils, 55 , 213-227. 
Shao, Y., Zhang, W., Eisenhauer, N., Liu, T., Xiong, Y., Liang, C., et al. (2017) Nitrogen deposition cancels out exotic earthworm effects on plant-feeding nematode communities. Journal of Animal Ecology, 86 , 708717.

Shaw, E.A., Boot, C.M., Moore, J.C., Wall, D.H. \& Baron, J.S. (2019) Long-term nitrogen addition shifts the soil nematode community to bacterivore-dominated and reduces its ecological maturity in a subalpine forest. Soil Biology and Biochemistry, 130, 177-184.

Shen, F., Wu, J., Fan, H., Liu, W., Guo, X., Duan, H., et al.(2019) Soil N/P and C/P ratio regulate the responses of soil microbial community composition and enzyme activities in a long-term nitrogen loaded Chinese fir forest. Plant and Soil, 436 , 91-107.

Sun, X., Zhang, X., Zhang, S., Dai, G., Han, S. \& Liang, W. (2013) Soil nematode responses to increases in nitrogen deposition and precipitation in a temperate forest. PLoS One, 8, e82468.

Todd, T.C., Powers, T.O. \&Mullin, P.G. (2006) Sentinel nematodes of land-use change and restoration in tallgrass prairie. Journal of Nematology, $38,20-27$.

Treonis, A.M., Unangst, S.K., Kepler, R.M., Buyer, J.S., Cavigelli, M.A., Mirsky, S.B., et al. (2018) Characterization of soil nematode communities in three cropping systems through morphological and DNA metabarcoding approaches. Scientific Reports, 8 , 2004.

van den Hoogen, J., Geisen, S., Routh, D., Ferris, H., Traunspurger, W., Wardle, D.A., et al. (2019) Soil nematode abundance and functional group composition at a global scale. Nature,572 , 194-198.

Vitousek, P.M., Aber, J.D., Howarth, R.W., Likens, G.E., Matson, P.A., Schindler, D.W., et al. (1997) Human alteration of the global nitrogen cycle: sources and consequences. Ecological Applications, 7 , 737-750.

Wei, C., Zheng, H., Li, Q., Lü, X.T., Yu, Q., Zhang, H., et al.(2012) Nitrogen addition regulates soil nematode community composition through ammonium suppression. PLoS One, 7 , e43384.

Wu, J., Liu, W., Fan, H., Huang, G., Wan, S., Yuan, Y., et al.(2013) Asynchronous responses of soil microbial community and understory plant community to simulated nitrogen deposition in a subtropical forest. Ecology and Evolution, 3 , 3895-3905.

Wu, J., Liu, W., Zhang, W., Shao, Y., Duan, H., Chen, B., Wei, X. \& Fan, H. (2019) Long-term nitrogen addition changes soil microbial community and litter decomposition rate in a subtropical forest.Applied Soil Ecology, 142, 43-51.

Xie, D., Zhao, B., Wang, S. \& Duan, L. (2020) Benefit of China's reduction in nitrogen oxides emission to natural ecosystems in East Asia with respect to critical load exceedance. Environment International, 136 , 105468.

Yang, Y., Cheng, H., Gao, H. \& An, S. (2020) Response and driving factors of soil microbial diversity related to global nitrogen addition.Land Degradation 8 Development, 31 , 190-204.

Yeates, G.W., Bongers, T., De Goede, R.G., Freckman, D.W. \& Georgieva, S.S. (1993) Feeding habits in soil nematode families and genera-an outline for soil ecologists. Journal of Nematology, 25, 315-331.

Yu, G., Jia, Y., He, N., Zhu, J., Chen, Z., Wang, Q., . . \& Goulding, K. (2019) Stabilization of atmospheric nitrogen deposition in China over the past decade. Nature Geoscience, 12 , 424-429.

Zhao, A., Liu, L., Xu, T., Shi, L., Xie, W., Zhang, W., et al.(2018) Influences of canopy nitrogen and water addition on AM fungal biodiversity and community composition in a mixed deciduous forest of China. Frontiers in Plant Science, $\mathbf{9}, 1842$.

Zhao, C., Fu, S., Mathew, R.P., Lawrence, K.S. \& Feng, Y. (2015a) Soil microbial community structure and activity in a 100-year-old fertilization and crop rotation experiment. Journal of Plant Ecology, 8, 623-632. 
Zhao, C., Zhao, J., Wu, J., Classen, A.T., Li, Y., Lou, Y., et al. (2019) Bamboo forest management leads to a shift in the soil energy channel. Geoderma, 353, 201-203.

Zhao, J., Neher, D.A., Fu, S., Li, Z. \& Wang, K. (2013) Non-target effects of herbicides on soil nematode assemblages. Pest Managemant Science, 69, 679-684.

Zhao, J., Wan, S., Li, Z.a., Shao, Y., Xu, G., Liu, Z., et al.(2012) Dicranopteris-dominated understory as major driver of intensive forest ecosystem in humid subtropical and tropical region. Soil Biology and Biochemistry, 49 , 78-87.

Zhao, J., Wang, F., Li, J., Zou, B., Wang, X., Li, Z., et al.(2014) Effects of experimental nitrogen and/or phosphorus additions on soil nematode communities in a secondary tropical forest. Soil Biology and Biochemistry, 75 , 1-10.

Zhao, J., Zhao, C., Wan, S., Wang, X., Zhou, L. \& Fu, S. (2015b) Soil nematode assemblages in an acid soil as affected by lime application.Nematology, $\mathbf{1 7}, 179-191$.

Zhou, Q., Li, F., Cai, X., Rao, X., Zhou, L., Liu, Z., et al.(2019). Survivorship of plant species from soil seedbank after translocation from subtropical natural forests to plantation forests. Forest Ecology and $M a$ nagement, 432, 741-747.

Zhou, Q.\& Wu, J. (2020). Long-term nitrogen addition alters the community and energy channel but not diversity of soil nematodes in a subtropical forest, Dryad, Dataset, https://doi.org/10.5061/dryad.x3ffbg7gg

\section{Figure legends}

Figure 1 . Abundance of nematode trophic groups as affected by $\mathrm{N}$ treatments and soil depth. Treatment and soil depth from two-way ANOVA are provided in each subpanel. Within each depth, different lowercase letters indicate significant differences of means $(P<0.05)$ under a LSD test among $\mathrm{N}$ treatments. Bars indicate standard errors of means $(n=3)$.

Figure 2. The diversity of soil nematodes as affected by $\mathrm{N}$ treatments and soil depth. Treatment and soil depth from two-way ANOVA are provided in each subpanel. Different uppercase letters indicate significant differences of means $(P<0.05)$ under a LSD test among soil depths. Bars indicate standard errors of means $(n=3)$.

Figure 3. Ecological indices of soil nematodes as affected by $\mathrm{N}$ treatments and soil depth. Treatment and soil depth from two-way ANOVA are provided in each subpanel. Within each depth, different lowercase letters indicate significant differences of means $(P<0.05)$ under a LSD test among $\mathrm{N}$ treatments. Bars indicate standard errors of means $(n=3)$.

Figure 4. The co-occurrence networks of nematode genera under different $\mathrm{N}$ treatments (a) and the robustness of nematode genera networks under different treatments (b). The size of each node indicates the proportion of total nematode abundance represented by the indicated genus. BF: bacterial-feeding nematodes; FF: fungal-feeding nematodes; PF: plant-feeding nematodes; OP: omnivorous-predatory nematodes.

Figure 5. Structural equation model (SEM) examining the direct and indirect effects of $\mathrm{N}$ addition on nematode trophic groups (a) and the standardized total effects (direct plus indirect effects) of each nematode trophic group derived from the SEM (b-e). Black and red lines indicate positive and negative effects, respectively. Line thickness in SEM indicates the strength of significant path coefficient and gray lines present the non-significant paths. Values associated with arrows are standardized path coefficients. $r^{2}$ values linked with response variables indicate the proportion of variation explained by relationships with other variables. PCT: the first component of TC, TN and TP determined by principal component analysis; PCA: the first component of AP, $\mathrm{NO}_{3}{ }^{+}-\mathrm{N}$ and $\mathrm{NH}_{4}{ }^{+} \mathrm{N}$ determined by principal component analysis; FF: fungal-feeding nematodes; $\mathrm{BF}$ : bacterial-feeding nematodes; PF: plant-feeding nematodes; OP: omnivorous-predatory nematodes. ${ }^{* * *} P<0.001,{ }^{* *} P<0.01,{ }^{*} P<0.05, n=36$. 


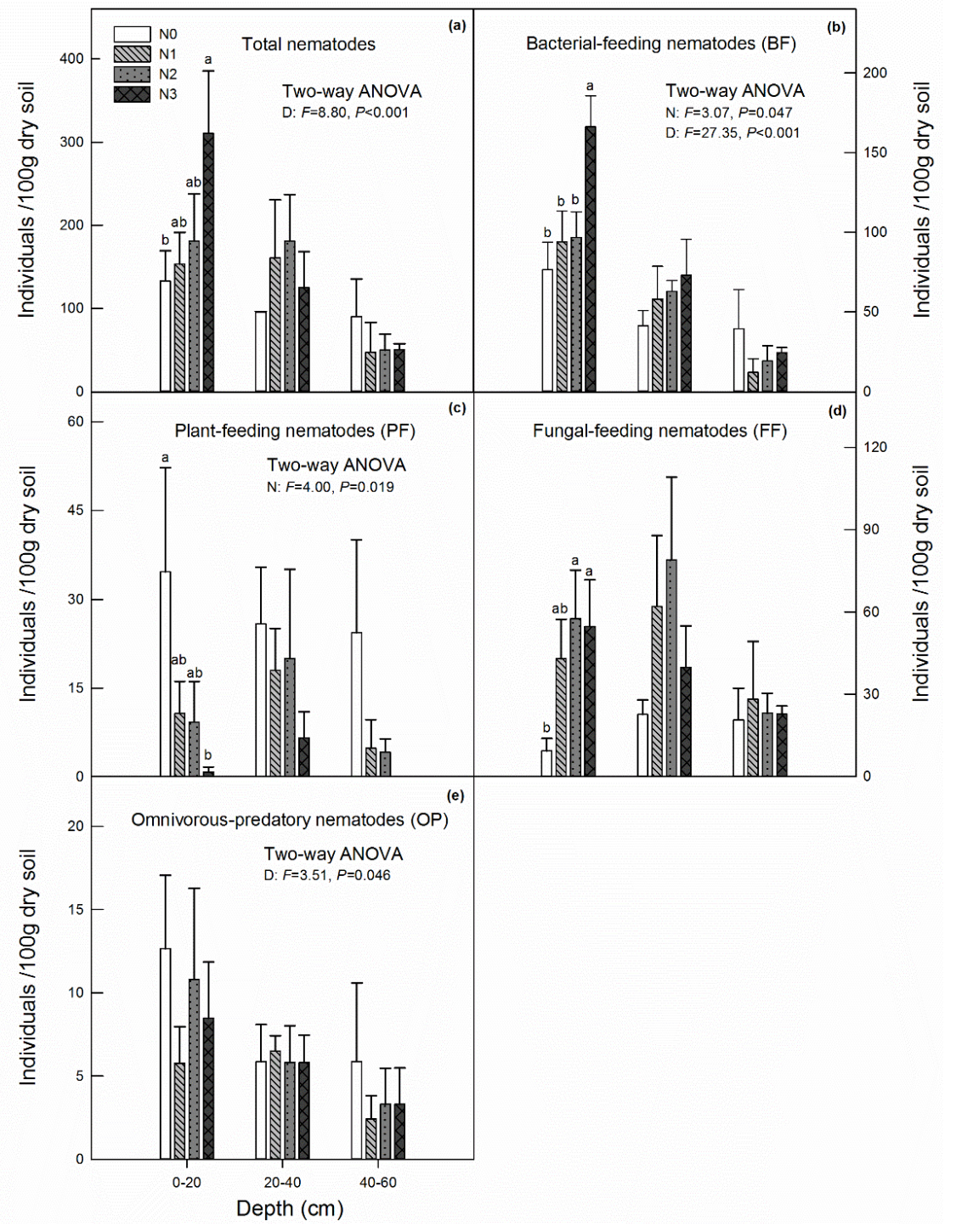

Figure 1 


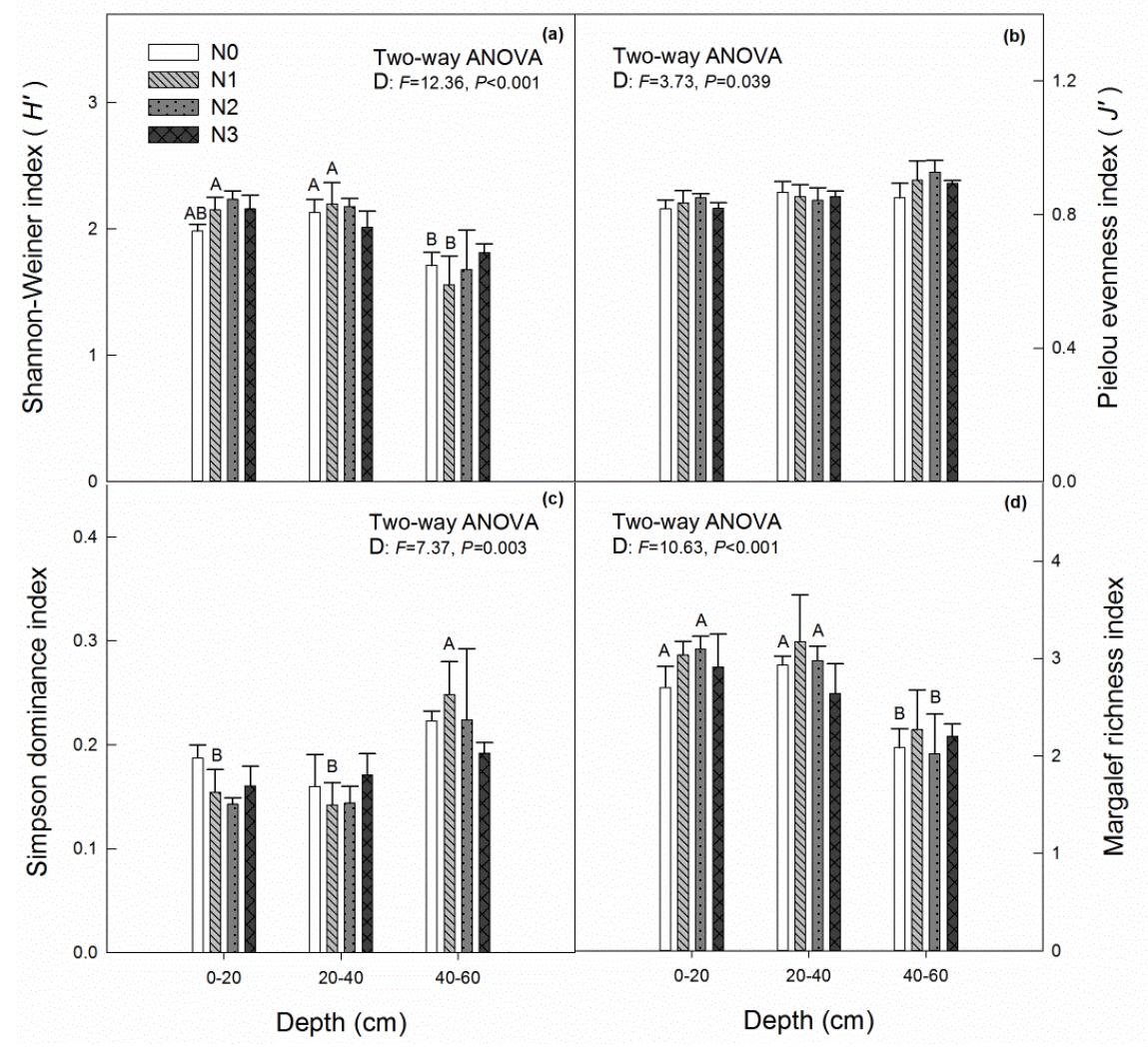

Figure 2 


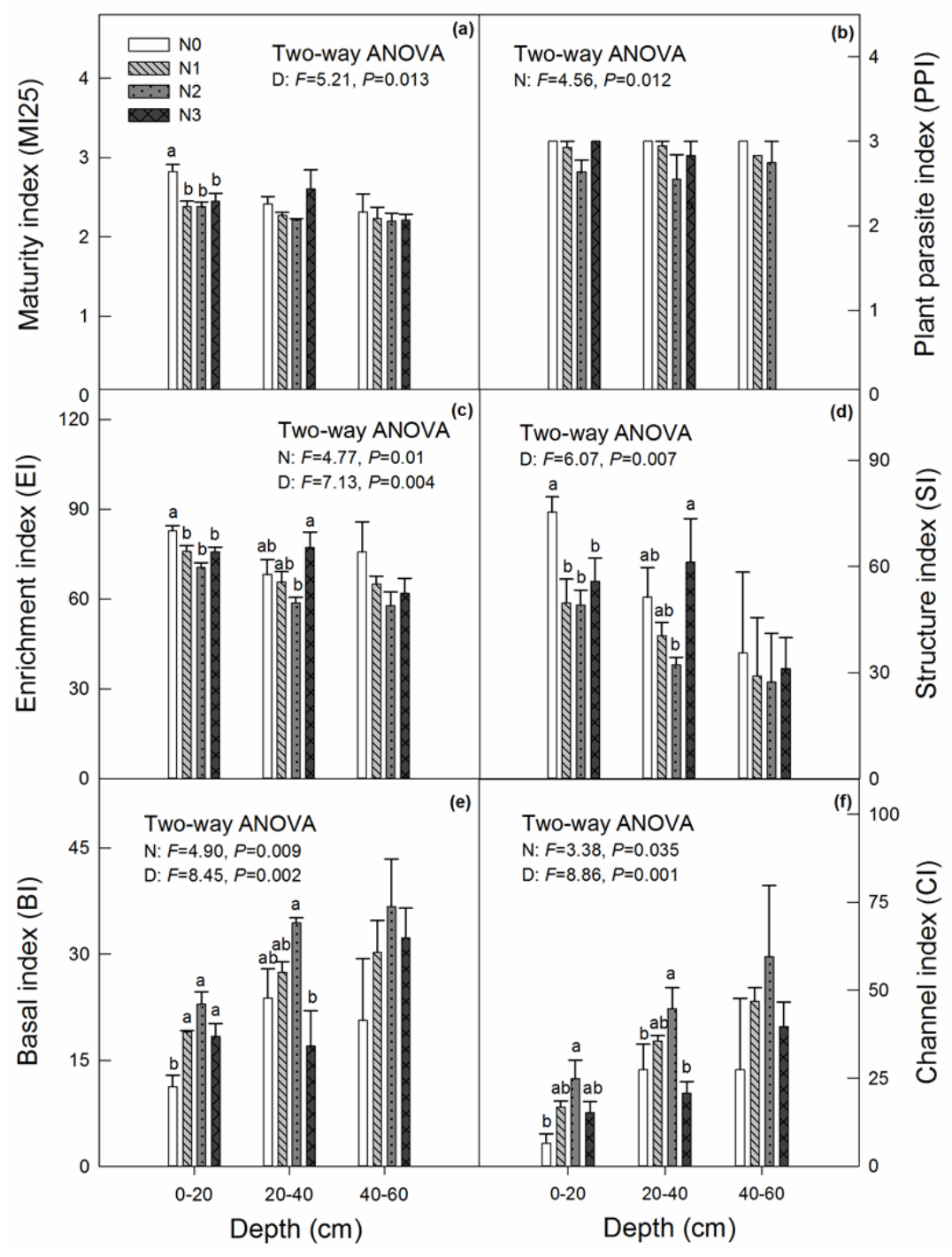

Figure 3 

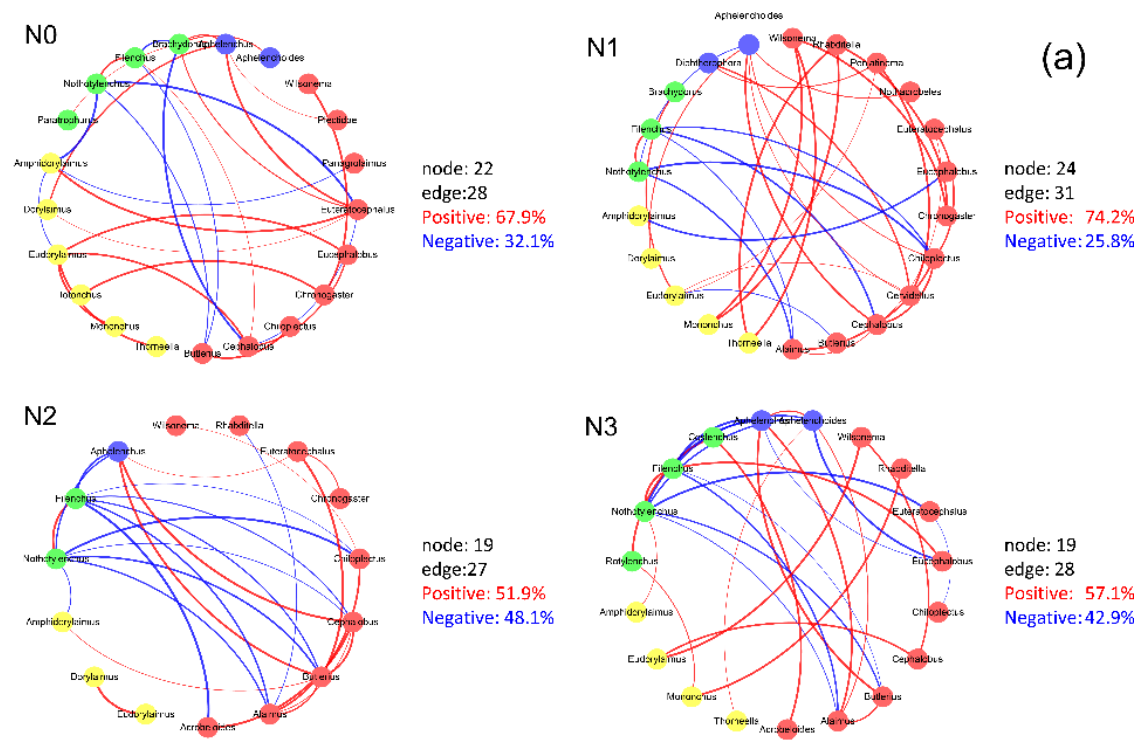

$\bigcirc \mathrm{BF} \bigcirc \mathrm{PF} \quad \mathrm{OP}$

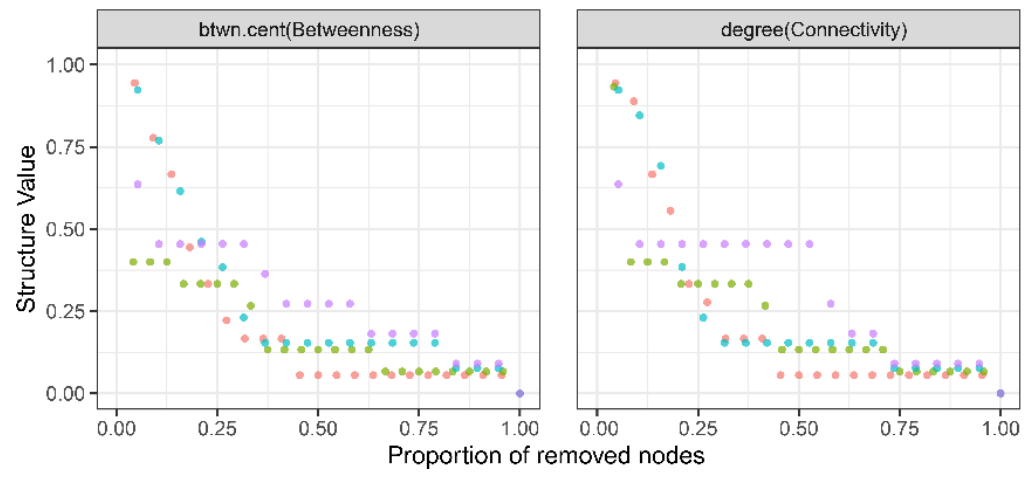

(b)

Type

NO

N1

- N2

N3

Figure 4
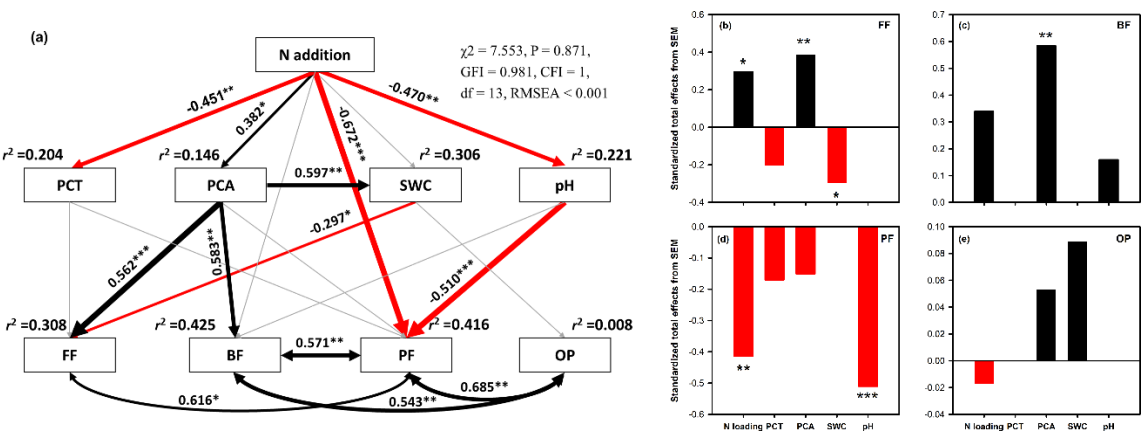

Figure 5 